\title{
Proposição e Análise de um Modelo para Comportamentos de Cidadania Organizacional
}

\author{
Mirlene Maria Matias Siqueira
}

\section{ResUMO}

Comportamentos de cidadania organizacional é uma expressão utilizada para representar ações informais dos trabalhadores que beneficiam a organização. Diversos estudos já procuraram apresentar evidências acerca dos fatores responsáveis pela emissão destes atos. No presente estudo, foi desenvolvido um modelo teórico para esta classe de ações, composto por antecedentes de natureza cognitiva e afetiva, visando a estabelecer uma interdependência entre os fatores psicossociais que emergem no contexto de trabalho e antecedem atos de cidadania nas organizações. O estudo contou com a participação de 520 trabalhadores de empresas públicas e particulares sediadas em Minas Gerais, que responderam a um instrumento que contém sete escalas de medida das variáveis integrantes do modelo. Os dados foram analisados por meio de modelos de regressão múltipla hierárquica e stepwise. Os resultados confirmaram as duas suposições do estudo, revelando que as cognições sobre a organização constituem a base informacional que influencia os afetos que o empregado nutre pelo trabalho que executa e pela empresa empregadora e que estes elos afetivos, por sua vez, mostraram-se capazes de predizer cinco classes de comportamentos de cidadania organizacional.

Palavras-chaves: comportamentos de cidadania organizacional; modelo pós-cognitivo; troca social.

\begin{abstract}
Organizational citizenship behaviors are an expression used to represent workers' informal acts that benefit the organization. Several studies have shown evidence of the factors which are responsible for the emission of these actions. In the present study a theoretical model for this class of actions has been developed, made up of cognitive and affective antecedents, aiming at establishing interdependence between the psychosocial factors which emerge in the work context and they precede citizenship actions in the organizations. 520 workers of public and private companies from Minas Gerais, Brazil, took part in the study. They answered a questionnaire with seven measuring scales of the model variables. The data were analysed according to the hierarchical multiple regression and the stepwise models. The results confirmed the two hypotheses of the study, showing that the cognitions about the organization constitute the informational basis with will influence the affect the employee nurtres for the work he performs and for the company employer, and that these affective links, for its turn, have been able to predict five classes of organizational citizenship behaviors.
\end{abstract}

Key words: organizational citizenship behaviors; pos cognitive model; social exchange. 


\section{INTRODUÇÃO}

A literatura sobre comportamentos de cidadania organizacional revela um consenso entre estudiosos, quando concebem gestos de cidadania como atos prósociais dos empregados dirigidos às organizações empregadoras (Organ, 1990; Moorman, 1991). Imbuídos dessa noção, pesquisadores (Smith, Organ e Near, 1983; Organ e Konovsky, 1989) procuraram identificar os seus antecedentes entre os fatores psicológicos que representassem afetividade (estado de ânimo e satisfação no trabalho), ou entre os elementos da cognição, dando-se maior ênfase, nestes casos, às variáveis relacionadas à percepção de justiça no contexto organizacional (Moorman, 1991).

Observam-se divagações dos estudiosos que, apesar dos esforços para compreender a associação entre comportamentos de cidadania e seus antecedentes, não utilizaram um referencial teórico para conceber a natureza das ações de cidadania e se dispersaram no momento de indicar os seus prováveis fatores antecedentes.

A conduta aqui adotada, ao se formalizar um modelo teórico para gestos de cidadania no contexto organizacional, seguiu uma linha diferente. A primeira preocupação foi a de conceber a natureza teórica do critério comportamental, tomando-se como referencial as teorias de troca social. Dentro desta abordagem, comportamentos de cidadania são entendidos como atos de troca social, oferecidos voluntariamente pelos trabalhadores às organizações. Eles constituiriam gestos de colaboração espontânea que, isentos de prescrições legais ou contratuais, permitiriam, dentro de uma relação social com a organização, entabular uma permuta de atos extrapapéis funcionais por possíveis ou futuras retribuições sociais, materiais ou econômicas da organização. Com esta concepção, descarta-se a possibilidade de que gestos de cidadania organizacional sejam atos altruísticos, mas reafirma-se a noção de que eles se constituam em atos eminentemente sociais dos empregados que beneficiam o sistema empregador, podendo, no futuro, ser retribuídos, ou não, pela organização.

Concebidos como atos envolvidos numa troca social com a organização, as suposições acerca das origens de tais gestos foram assentadas numa base informacional (cognitivista) que representasse concepções do empregado sobre a organização, como um objeto social com o qual ele mantém permuta. Desse modo, as cognições posicionadas no modelo, para compor a base informacional, foram as noções com as quais o empregado estruturaria suas concepções sobre 
a organização dentro de uma relação social. Com este posicionamento teórico, o modelo para analisar os antecedentes de atos de cidadania propõe que cognições favoráveis sobre a organização sejam a base de um processo psicológico que culminaria com a emissão de atos de colaboração espontânea, ou seja, gestos de cidadania organizacional.

\section{Pressupostos de Estruturação do Modelo}

Admitindo-se a possibilidade de que cognições favoráveis sobre a organização possam desencadear reações afetivas no empregado, o modelo aqui desenvolvido para gestos de cidadania inclui a presença de variáveis afetivas perante o trabalho executado e a empresa empregadora. Deve-se ressaltar, contudo, que as variáveis afetivas do modelo não são de natureza disposicional, que incluem traços pessoais dos trabalhadores, mas sentimentos que emergem no contexto de trabalho. Desta forma, foge-se da tendência de atribuir capacidade preditiva às variáveis disposicionais sobre gestos de cidadania; mantém-se, contudo, o propósito de analisar com visão pós-cognitiva, que inclui o pressuposto de serem as cognições antecedentes dos estados afetivos (Lazarus, 1982), a interdependência de fatores cognitivos e afetivos que emergem nas relações de troca empregadoorganização como elementos psicológicos do processo que antecede atos de cidadania organizacional.

Ao se restringirem as reações afetivas àquelas que emergem em situações de trabalho, como satisfação no trabalho, envolvimento com o trabalho e comprometimento afetivo com a organização e que, tradicionalmente, têm sido apontadas na literatura pertinente como antecedentes da conduta humana no trabalho, cria-se a possibilidade de, mais adequadamente, estruturar uma proposta de microanálises do comportamento organizacional.

Concebendo-se ações de cidadania como critério comportamental volitivo, está sendo admitido que tais condutas estejam sob o controle individual. Rejeita-se, portanto, a possibilidade de que estes atos sejam automáticos ou impensados. Embora de natureza volitiva, eles só seriam espontaneamente emitidos, se o empregado vivenciasse sentimentos positivos sobre o trabalho que executa e mantivesse vínculos afetivos positivos com a organização. Assim, especialmente por sua natureza volitiva, os fatores capazes de diretamente predizer variações neste critério comportamental seriam as intenções comportamentais, entendidas como planos de ação a ele associadas.

Com base nos pressupostos anteriormente apresentados, o modelo teórico para 
comportamentos de cidadania, principal objeto de análise deste trabalho, foi concebido para representar um processo psicológico de troca social entre empregado e organização, que se inicia pela formação de cognições seguidas de afetos que, por sua vez, favorecem a elaboração de intenções comportamentais estritamente associadas ao critério comportamental. O modelo possui uma estrutura composta por elementos cognitivos, afetivos, intencionais e comportamentais. Contudo, quando houver interesse e oportunidade de se quantificar os atos de cidadania, seria dispensada a mensuração das intenções a eles associadas (vide Figura 1).

\section{Figura 1: Modelo Pós-Cognitivo para Comportamentos de Cidadania Organizacional}

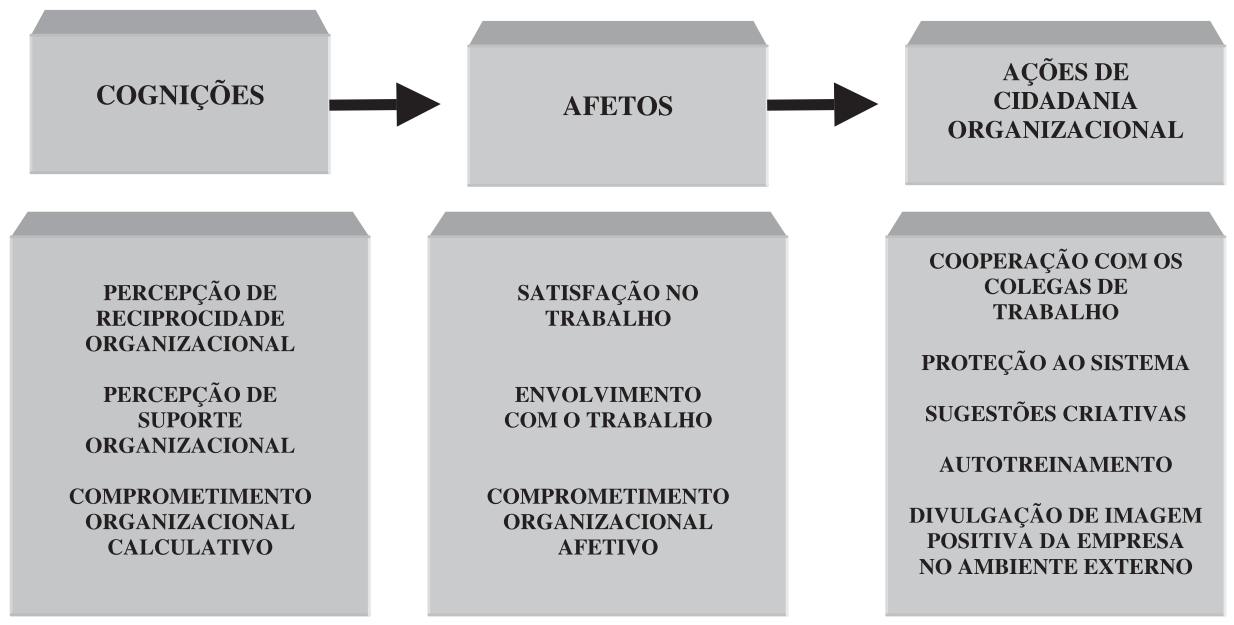

\section{Comportamentos de Cidadania Organizacional}

Comportamentos de cidadania organizacional são definidos como um conjunto de ações espontâneas dos empregados, as quais trazem conseqüências benéficas à organização como um todo, não incluídas nas exigências do papel formal, nem nos esquemas formais de recompensas e sanções previstos pela organização. Cinco classes de ações, apontadas por Katz e Kahn (1978) como integrantes do comportamento inovador e espontâneo, foram escolhidas para nominar as dimensões comportamentais de cidadania organizacional:

. atividades de cooperação com os demais membros do sistema;

. ações protetoras do sistema ou subsistema; 


\section{. sugestões criativas para melhoria organizacional;}

\section{. autotreinamento para maior responsabilidade organizacional;}

\section{. criação de clima favorável para a organização no ambiente externo.}

O conjunto de ações acima apontado constitui a forma diferenciada com que o empregado manifesta, nas suas ações, uma troca social com a organização.

\section{Os Elos Afetivos}

Como não basta predizer um dado comportamento, mas é necessário buscar explicações para as intenções que a ele se associam (Ajzen e Fishbein, 1980), supõe-se que os afetos dirigidos ao trabalho executado e a organização sejam os antecedentes diretos de comportamentos de cidadania. Na Figura 1 foram apontadas as variáveis satisfação no trabalho e envolvimento com o trabalho como dois tipos de afetos em face do trabalho e comprometimento organizacional afetivo como componente afetivo dirigido à organização. A escolha recaiu sobre estas três variáveis por duas razões: em primeiro lugar, elas são repetidamente apontadas na literatura do comportamento organizacional como sendo de natureza afetiva e, adicionalmente, porque se supõe que um empregado satisfeito, envolvido com o seu trabalho e que mantém laços afetivos com seu empregador (comprometimento afetivo) teria maiores possibilidades de intentar apresentar atos de colaboração com o sistema, ou seja, de se comportar como um cidadão organizacional.

\section{As Cognições}

Considera-se que as cognições dos empregados acerca das relações de troca social que mantêm com a organização, sejam os antecedentes psicológicos das variáveis afetivas. Supõe-se que quando o empregado acredita que a interrupção desta relação acarretaria custos para si mesmo, que a organização se preocupa com o seu bem-estar e se comporta de forma recíproca a seus atos espontâneos de trabalho, então ele estaria cognitivamente apto a desenvolver elos afetivos com o trabalho executado e com a organização empregadora. Para figurar como variáveis cognitivas no modelo, escolheram-se três conceitos derivados das teorias de troca social:

- comprometimento organizacional calculativo, derivado da teoria de sidebets de Becker (1960), que compreende crenças relativas a perdas ou custos associados ao rompimento da relação de troca com a organização; 
- percepção de suporte organizacional, composto por um conjunto de crenças sobre o grau em que a organização se mostra comprometida com os empregados (Eisenberger et al., 1986);

- percepção de reciprocidade organizacional, um conceito derivado do princípio de reciprocidade (Gouldner, 1960), concebido pela autora deste trabalho (Siqueira, 1995) como um conjunto de crenças acerca do estilo retributivo adotado pela organização perante as contribuições ofertadas por seus empregados.

O modelo aqui proposto engloba a noção de que as relações entre cognições e afetos são pós-cognitivas (Lazurus, 1982) e bidirecionais. Esta idéia significa que afetos relativos ao trabalho (satisfação no trabalho e envolvimento com o trabalho) e à organização (comprometimento organizacional afetivo) seriam desencadeados por cognições formadas sobre a organização, especialmente aquelas derivadas das interações de troca entabuladas entre empregado e organização. Por outro lado, os elos afetivos desenvolvidos poderiam influir retroativamente sobre as cognições dos empregados acerca da organização, provocando, em conseqüência, uma relação bidirecional entre cognições e afetos.

Feita a apresentação dos componentes estruturais do modelo pós-cognitivo para comportamentos de cidadania organizacional, será apresentado, a seguir, um estudo que tomou essa classe de ações como objeto de análise e produziu evidências empíricas acerca das suposições do referido modelo. Buscar evidências empíricas para as relações supostas entre as variáveis contidas no referido modelo, constitui o principal objetivo deste estudo.

\section{Metodologia}

\section{Participantes}

A realização do presente estudo contou com a participação de uma amostra escolhida ao acaso, composta de 520 trabalhadores, sendo 51,3\% do sexo masculino, $51,0 \%$ casados, com escolaridade variando de $1^{\circ}$ grau completo $(3,5 \%)$ a superior completo (33,1\%), idade média de 32,2 anos ( $\mathrm{DP}=13,89)$ e tempo médio de serviço de 9 anos $(\mathrm{DP}=1,01)$ nas respectivas organizações empregadoras. Os trabalhadores eram empregados de 16 organizações distintas, sendo 11 privadas (68,75\%), 4 públicas (25\%) e uma de economia mista (6,25\%), situadas em Minas Gerais nas regiões do Alto Paranaíba e do Triângulo Mineiro. 


\section{Hipóteses}

As suposições acerca da interdependência das variáveis integrantes do modelo para comportamentos de cidadania organizacional levaram à formulação das seguintes hipóteses:

. H1: Comportamentos de cidadania organizacional têm como antecedentes diretos as variáveis afetivas satisfação no trabalho, envolvimento com o trabalho e comprometimento organizacional afetivo.

. H2: As variáveis afetivas do modelo têm como antecedentes as cognições percepção de reciprocidade organizacional, percepção de suporte organizacional e comprometimento organizacional calculativo.

\section{Instrumento de Coleta de Dados}

A coleta de dados foi efetuada por meio de um questionário com três partes. A primeira continha a apresentação do estudo, instruções gerais para responder a ele e o endereço da pesquisadora. A segunda compunha-se de 70 itens integrantes de sete escalas distintas.

Escala de Comportamentos de Cidadania Organizacional: desenvolvida e validada por Siqueira (1995), a escala é composta por 18 frases, representando 5 fatores, dos quais 3 detêm índices frágeis de precisão: criação de clima favorável à organização no ambiente externo $(\alpha=0,76)$; sugestões criativas ao sistema $(\alpha=0,74)$; proteção ao sistema $(\alpha=0,64)$; autotreinamento $(\alpha=0,51)$ e cooperação com colegas de trabalho $(\alpha=0,51)$.

. Escala de Satisfação no Trabalho: a medida, desenvolvida e validada por Siqueira (1995), é composta por 25 frases, que descrevem 5 fatores: satisfação com colegas de trabalho $(\alpha=0,86)$; satisfação com salário $(\alpha=0,92)$; satisfação com a chefia $(\alpha=0,90)$; satisfação com a natureza do trabalho $(\alpha=0,82)$ e satisfação com promoções $(\alpha=0,87)$. Neste estudo foi usada a versão reduzida da medida, com 15 itens, cujos fatores tiveram índices de precisão entre 0,77 e 0,90 .

. Escala de Envolvimento com o Trabalho: a medida é composta por 5 frases, com índice de precisão de 0,78 (Siqueira, 1995).

Escala de Percepção de Suporte Organizacional: esta medida foi originalmente desenvolvida por Eisenberger et al. (1986) e adaptada e validada para o meio brasileiro por estudos desenvolvidos por Siqueira (1995), ficando sua ver- 
são brasileira constituída por 9 itens $(\alpha=0,86)$. Neste estudo foi usada sua versão reduzida, com 6 itens, com índice de precisão de 0,86 .

- Escala de Percepção de Reciprocidade Organizacional: a medida contém 18 frases, com índice de precisão de 0,97 , tendo sido construída e validada por Siqueira (1995). Neste estudo foi utilizada sua forma reduzida, com 6 frases $(\alpha=0,94)$.

- Escala de Comprometimento Organizacional Afetivo: composta por 18 frases $(\alpha=0,95)$, a medida foi desenvolvida e validada por Siqueira (1995). No estudo foi utilizada sua forma reduzida, composta por 5 frases $(\alpha=0,93)$.

- Escala de Comprometimento Organizacional Calculativo: desenvolvida e validada por Siqueira (1995), a medida é composta por 15 frases, que representam 4 fatores: perdas sociais no trabalho $(\alpha=0,72)$; perdas de investimentos feitos na organização $(\alpha=0,71)$; perdas de retribuições organizacionais $(\alpha=0,71)$ e perdas profissionais $(\alpha=0,78)$.

A terceira e última parte do questionário objetivava levantar dados pessoais (sexo, idade, estado civil e grau de instrução) e funcionais (tempo de serviço na organização, tipo e empresa) dos participantes do estudo.

\section{Procedimento de Coleta de Dados}

Durante o recolhimento dos dados, contatos foram estabelecidos com 26 organizações situadas em Minas Gerais. Deste total, apenas 16 autorizaram a participação dos trabalhadores na pesquisa.

A distribuição e o recolhimento dos questionários ocorreram nos próprios locais de trabalho dos participantes, em horários previamente acertados com os dirigentes das organizações. No momento da entrega dos questionários aos trabalhadores, era enfatizado que a pesquisa estava totalmente desvinculada da organização empregadora, constituindo-se, tão somente, num estudo de caráter científico.

Aos trabalhadores foi também esclarecido que a sua participação era espontânea, cabendo a eles a decisão de colaborar, ou não, com a pesquisa. No momento da distribuição dos instrumentos, eram combinadas as datas de sua devolução, com prazo que variava de dois a sete dias, conforme o número de participantes de cada organização. Um total de 860 questionários foi distribuído, retornando apenas 541 , dos quais 21 estavam incompletos, o que resultou em 520 susceptíveis de aproveitamento. 


\section{Análise dos Dados}

Os dados recolhidos para a realização do presente estudo, todos representados no questionário por indicadores numéricos, permitiram a sua direta transposição para um banco de dados e posterior processamento. Durante a execução das análises estatísticas foram utilizados diversos subprogramas do Statistical Package for the Social Sciences (SPSS).

Para testar a primeira hipótese do estudo foram calculados dez modelos de regressão múltipla hierárquica. Para averiguar o quanto cada variável afetiva (satisfação no trabalho, envolvimento com o trabalho e comprometimento afetivo) explicava da variância particular dos cinco fatores de cidadania, cinco modelos de regressão múltipla stepwise foram calculados.

Dando prosseguimento às análises do modelo, as três variáveis afetivas (satisfação no trabalho, envolvimento com o trabalho e comprometimento afetivo) foram colocadas como variáveis dependentes em três modelos particulares de regressão múltipla (stepwise) tendo, cada uma, como regressores as cognições percepção de reciprocidade, percepção de suporte e comprometimento calculativo. Nesta etapa se buscava testar a segunda hipótese do estudo, identificando quanto cada regressor cognitivo acrescia à variância explicada das variáveis afetivas.

\section{Resultados}

\section{Correlações entre as Variáveis}

A Tabela 1 contém coeficientes de correlação bivariados ( $\mathrm{r}$ de Pearson). Observam-se correlações positivas e significativas entre os cinco fatores de cidadania e as variáveis afetivas satisfação no trabalho, envolvimento com o trabalho e comprometimento afetivo, variando de 0,12 a 0,56 . O mesmo não ocorre com relação às variáveis de natureza cognitiva com as quais os cinco fatores de cidadania apresentam correlações significativas mais fracas, entre 0,07 e 0,41 , observando-se até mesmo associações não significativas entre algumas delas e quatro dos cinco fatores de cidadania.

Dentro do bloco de variáveis afetivas existem correlações positivas e significativas entre todas elas, o mesmo ocorrendo entre as variáveis do bloco cognitivo. As correlações entre estes dois blocos de variáveis são também positivas e significativas, destacando-se como valores mais elevados as associações entre percepção de suporte e as variáveis afetivas satisfação no trabalho, envolvimento com o tra- 
balho e comprometimento afetivo. Estes resultados sinalizam o seguinte: quanto mais o empregado percebe positivamente a organização, mais ele se sente ligado afetivamente ao trabalho que executa e à organização que o emprega.

\section{Tabela 1: Coeficientes de Correlação (r de Pearson) entre os Cinco Fatores de Comportamentos de Cidadania Organizacional e seus Antecedentes Afetivos e Cognitivos}

\begin{tabular}{|c|c|c|c|c|c|c|}
\hline VARIÁVEIS & \multirow[b]{2}{*}{ ST } & \multirow[b]{2}{*}{ ET } & \multirow[b]{2}{*}{ COA } & \multirow[b]{2}{*}{ PRO } & \multirow[b]{2}{*}{ PSO } & \multirow[b]{2}{*}{$\mathrm{COC}$} \\
\hline $\begin{array}{l}\text { Fatores de Comportamentos de Cidadania } \\
\text { Organizacional: }\end{array}$ & & & & & & \\
\hline - Fator 1 - Clima Favorável à Organização & $0,35^{* *}$ & $0,41 * *$ & $0,56^{* *}$ & $0,23 * *$ & $0,41 * *$ & $0,20 * *$ \\
\hline - Fator 2 - Sugestões Criativas ao Sistema & $0,13^{*}$ & 0,12 & 0,16 & $-0,01$ & 0,05 & $-0,02$ \\
\hline - Fator 3 - Proteção ao Sistema & $0,18 * *$ & $0,12 * *$ & $0,16^{* *}$ & $-0,02$ & $0,07 *$ & 0,01 \\
\hline - Fator 4 - Autotreinamento & $0,24 * *$ & 0,25 & 0,24 & 0,04 & $0,15 * *$ & $0,08 *$ \\
\hline $\begin{array}{l}\text { - Fator 5 - Cooperação com Colegas de } \\
\text { Trabalho }\end{array}$ & $0,17 * *$ & $0,20 * *$ & $0,23 * *$ & $0,07 *$ & $0,09^{*}$ & 0,05 \\
\hline
\end{tabular}

\section{Antecedentes Afetivos}

Satisfação no Trabalho (ST)

Envolvimento com o Trabalho (ET)

Comprometimento Organizacional Afetivo $0,59 * * 0,5 \overline{1} * *$

(COA)

Antecedentes Cognitivos

Percepção de Reciprocidade Organizacional $0,36^{* *} \quad 0,30 * * \quad 0,38^{* *} \quad \ldots$

(PRO)

Percepção de Suporte Organizacional (PSO) $\quad 0,56 * * \quad 0,47 * * \quad 0,60 * * \quad 0,42 * *$

$\begin{array}{lllllll}\text { Comprometimento Organizacional Calculativo } & 0,23 * * & 0,24 * * & 0,34^{* *} & 0,25 * * & 0,24 * *\end{array}$

(COC)

${ }^{* *} \mathrm{p}<0,01 ; * \mathrm{p}<0,05$

Os resultados da matriz de correlação demostram também que as cinco classes de comportamentos de cidadania estão mais fortemente associadas às variáveis afetivas do que às variáveis cognitivas, fortalecendo a suposição de que os elos afetivos sejam os seus antecedentes diretos, hipótese a ser testada com maior probabilidade por meio de modelos de regressão múltipla hierárquica, descritos a seguir.

\section{Antecedentes Diretos de Comportamentos de Cidadania Organizacional}

Análises de regressão múltipla hierárquica permitiram verificar a veracidade da hipótese de que as variáveis afetivas eram os antecedentes diretos de cada classe de comportamentos de cidadania organizacional, porque seriam capazes de prover maiores porcentagens de explicação da variância dos cinco fatores do que as variáveis de natureza cognitiva. 
Para cada fator um dos cinco fatores da Escala de Comportamentos de Cidadania Organizacional, considerados como variáveis dependentes, as variáveis afetivas (satisfação no trabalho, envolvimento com o trabalho e comprometimento afetivo) e as cognitivas (percepção de reciprocidade organizacional, percepção de suporte organizacional e comprometimento organizacional calculativo) foram comparadas em termos de incremento por elas produzido na variância explicada de cada fator, por meio de duas alternativas de análises que envolveram um total de dez modelos de regressão múltipla hierárquica.

Um exame da Tabela 2 mostra que na primeira alternativa, quando as variáveis afetivas constituíram o primeiro bloco de regressores, elas produziram valores mais elevados $\left(\mathrm{R}^{2}\right)$ do que as cognitivas para explicação de cada classe de comportamentos de cidadania. As contribuições das variáveis cognitivas mostraram-se não significativas, exceto o fator sugestões criativas, onde se observa uma contribuição significativa dos antecedentes cognitivos. Entretanto, mesmo neste fator, existe superioridade dos antecedentes afetivos sobre os cognitivos.

Na segunda alternativa de regressão múltipla hierárquica, vê-se que as variáveis afetivas, mesmo estando colocadas no segundo passo, acrescentaram contribuições significativas e superiores às cognitivas, que haviam entrado no primeiro passo. Apenas para o fator clima favorável à organização a contribuição das variáveis cognitivas superou a contribuição oferecida pelas variáveis afetivas.

Com estes resultados, fica evidenciado que os antecedentes afetivos detêm maiores proporções da variância explicada dos cinco fatores de comportamentos de cidadania organizacional do que os antecedentes cognitivos. Eles se constituem em seus antecedentes diretos como previsto pelo modelo (afetos $\otimes$ comportamentos de cidadania), confirmando, portanto, a primeira hipótese formulada para o presente estudo.

Os resultados aqui relatados dão suporte empírico para a estrutura pós-cognitiva prevista no modelo, visto que os antecedentes afetivos se associaram mais fortemente às cinco classes de comportamentos de cidadania do que os antecedentes cognitivos.

Existe, contudo, uma contradição entre os resultados deste estudo e aqueles apresentados por Organ e Konovsky (1989), quando os dois autores demonstraram, utilizando igualmente regressão múltipla hierárquica, serem os fatores cognitivos, e não os afetivos, os antecedentes diretos de comportamentos de cidadania organizacional. Naquele estudo os autores incluíram a escala de afeto positivo e negativo, desenvolvida por Watson e Tellegen (1985), solicitando aos sujeitos que a ela respondessem para indicar o seu estado de ânimo no trabalho. 
Sendo o estado de ânimo considerado uma variável disposicional (Watson e Clark, 1984; Watson e Tellegen, 1985), não poderia realmente ser capaz de anteceder diretamente um comportamento de trabalho, mas preceder às cognições do trabalhador sobre suas experiências no contexto organizacional. Assim, o fato de elos afetivos em face do trabalho (satisfação e envolvimento) e um relativo à organização (comprometimento afetivo) terem sido apontados pelos resultados do presente estudo como antecedentes diretos de cidadania organizacional nega, em parte, os achados de Organ e Konovsky (1989) e, ao mesmo tempo, encontra neles apoio para a suposição de que variáveis individuais são fatores externos ao modelo elaborado para comportamentos de cidadania, porque elas antecedem o processo psicológico de base informacional (cognitivista).

Tabela 2: Coeficientes de Correlação Múltipla $\left(\mathbf{R}^{2}\right)$ Obtidos em

Duas Alternativas de Regressão Múltipla Hierárquica sobre os Cinco Fatores de Comportamentos de Cidadania Organizacional

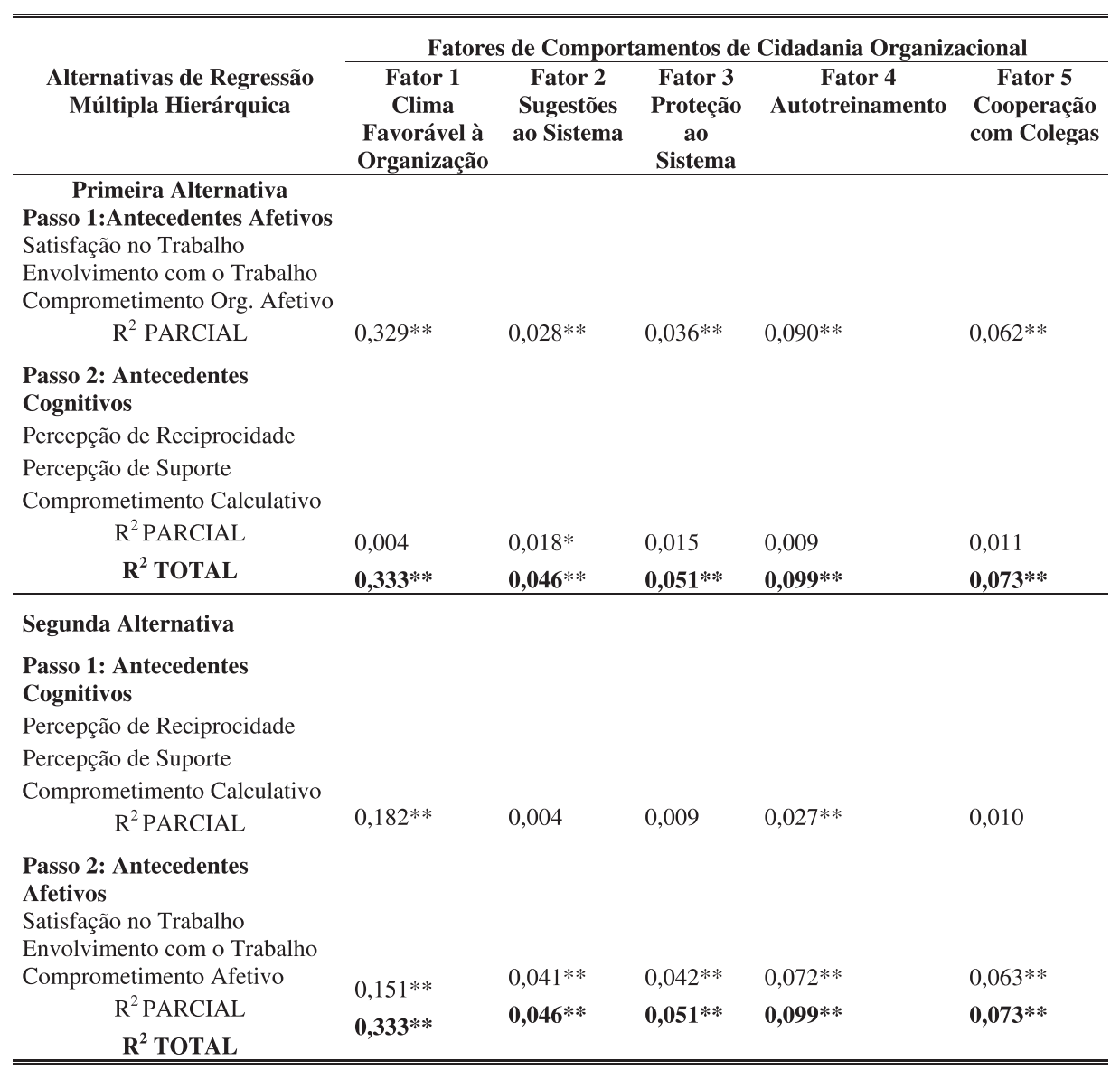

** $\mathrm{p}<0,01 ; * \mathrm{p}<0,05$. 


\section{Antecedentes Afetivos de Comportamentos de Cidadania Organizacional}

A Tabela 3 contém os resultados de cinco análises de regressão múltipla (stepwise) apontando, para cada modelo, a variável dependente, os regressores, os passos em que eles entraram na regressão, a sua contribuição particular para prover explicação para a variável dependente ( $\mathrm{R}^{2}$ parcial), o total de explicação provido pelo respectivo modelo ( $\mathrm{R}^{2}$ modelo) e o coeficiente de regressão (beta padronizado), que expressa quanto cada variável independente contribuiu para a predição do critério por meio de unidades em termos de desvio padrão.

\section{Tabela 3: Cinco Modelos de Regressão Stepwise sobre os Fatores de Cidadania Organizacional}

\begin{tabular}{|c|c|c|c|c|c|}
\hline $\begin{array}{c}\text { VARIÁVEIS } \\
\text { DEPENDENTES }\end{array}$ & Regressores & Passos & $\begin{array}{c}\mathbf{R}^{2} \\
\text { Parciais }\end{array}$ & $\begin{array}{c}\mathbf{R}^{2} \\
\text { Modelo } \\
\end{array}$ & $\begin{array}{c}\text { Betas } \\
\text { Padronizados }\end{array}$ \\
\hline \multicolumn{6}{|l|}{ 1. Fator 1: } \\
\hline Clima Favorável à & $\mathrm{COA}$ & 1 & $0,308^{* *}$ & $0,329 * *$ & $0,470^{* *}$ \\
\hline Organização & ET & 2 & $0,021 * *$ & & $0,166^{* *}$ \\
\hline \multicolumn{6}{|l|}{ 2. Fator 2: } \\
\hline Sugestões Criativas & $\mathrm{COA}$ & 1 & $0,025^{* *}$ & $0,025^{* *}$ & $0,157^{* *}$ \\
\hline \multicolumn{6}{|l|}{ 3. Fator 3: } \\
\hline Proteção do Sistema & ST & 1 & $0,031^{* *}$ & $0,031^{* *}$ & $0,177^{* *}$ \\
\hline 4. Fator 4: & ET & 1 & $0,063^{* *}$ & $0,085^{* *}$ & $0,170^{* *}$ \\
\hline Autotreinamento & ST & 2 & $0,022^{* *}$ & & $0,169^{* *}$ \\
\hline 5. Fator 5: & $\mathrm{COA}$ & 1 & $0,051^{* *}$ & $0,062^{* *}$ & $0,166^{* *}$ \\
\hline Cooperação com colegas & ET & 2 & $0,011 *$ & & $0,120 *$ \\
\hline
\end{tabular}

Nota: $\mathrm{n}=520 ; \mathrm{COA}=$ comprometimento organizacional afetivo; $\mathrm{ET}=$ envolvimento com o trabalho; $\mathrm{ST}=$ satisfação no trabalho. ${ }^{*} \mathrm{p}<0,01 ; * \mathrm{p}<0,05$.

Os gestos de divulgar ao público uma imagem positiva e favorável da organização empregadora (Fator 1 - clima favorável à organização) podem ser explicados em $30,8 \%$ pelo comprometimento organizacional afetivo e em $2,1 \%$ pelo envolvimento com o trabalho. Estes dois antecedentes afetivos totalizaram uma porcentagem da ordem de 32,9\% de explicação do Fator 1, compondo, em conseqüência, o modelo com maior índice de variância explicada, contido na Tabela 3. Nota-se que a variável satisfação no trabalho não foi retida neste modelo de regressão.

No segundo modelo de regressão, quando foi analisada a variância explicada de atos sugestivos e criativos visando à melhoria organizacional (Fator 2), constatou-se que apenas comprometimento afetivo com a organização foi retido no modelo, explicando $2,5 \%$ da variância do Fator 2, excluindo-se a participação de envolvimento com o trabalho e satisfação no trabalho. 
O Fator 3, composto por atos de proteção aos bens e patrimônio da organização, teve sua variância explicada em 3,1\% pelo grau de satisfação experimentado pelo empregado no seu trabalho atual. As variáveis comprometimento organizacional afetivo e envolvimento com o trabalho não foram mantidas como regressores no modelo.

Ações de autotreinamento, visando ao aperfeiçoamento profissional para executar tarefas requeridas pelo cargo ocupado, são uma classe de comportamentos de cidadania que teve sua variância explicada em $8,5 \%$ por dois regressores: envolvimento com o trabalho contribuiu com $6,3 \%$ e satisfação no trabalho com $2,2 \%$. A variável comprometimento organizacional afetivo não foi retida no modelo.

Gestos de colaboração com os colegas no ambiente de trabalho (Fator 5) puderam ser explicados em $6,2 \%$ pelo modelo de regressão, composto por comprometimento organizacional afetivo e envolvimento com o trabalho, os quais contribuíram, respectivamente, com $5,1 \%$ e $1,1 \%$ para explicar sua variância. Satisfação no trabalho ficou excluída como preditor neste último modelo de regressão.

Diante dos resultados aqui expostos, nota-se que, entre os cinco modelos de regressão analisados, nenhum deles pôde reter simultaneamente as três variáveis afetivas como antecedentes particulares dos cinco fatores de cidadania organizacional. Entre os regressores, destacam-se as contribuições da variável comprometimento organizacional afetivo que, além de ter sido mantida em três modelos de regressão, superou as contribuições de envolvimento com o trabalho na explicação da variância do Fator 1 (clima favorável) e do Fator 5 (cooperação com colegas) e revelou-se o preditor único do Fator 2 (sugestões criativas). Cabe ressaltar que o comprometimento com a organização não foi incluído em nenhum estudo como antecedente de cidadania organizacional. As contribuições da variável satisfação no trabalho foram irrisórias, considerando-se que, entre os três vínculos afetivos incluídos nestas análises, ela é a única freqüentemente apontada pelos pesquisadores internacionais (Bateman e Organ, 1983; Motowidlo, 1984; Puffer, 1987) como preditora de gestos de cidadania organizacional. Conforme os resultados do presente estudo, ela pode ser considerada a variável afetiva que apresentou menor poder preditivo, constituindo-se no antecedente mais frágil de cidadania organizacional. Estes resultados podem ter sido produzidos pelo efeito de multicolinearidade, visto que a variável percepção de suporte organizacional detém elevado índice de correlação com satisfação no trabalho e a supera no índice de correlação que mantém com algumas classes de comportamentos de cidadania. 


\section{Antecedentes Cognitivos das Variáveis Afetivas}

A segunda hipótese elaborada neste estudo afirmava serem os fatores cognitivos os antecedentes das variáveis afetivas (cognições $\bigotimes$ afetos). Para testá-la, três modelos de regressão múltipla stepwise foram calculados, tendo como variável dependente, respectivamente em cada um deles, comprometimento organizacional afetivo, envolvimento com o trabalho e satisfação no trabalho e, como regressores, as variáveis cognitivas percepção de suporte organizacional, percepção de reciprocidade organizacional e comprometimento organizacional calculativo.

A Tabela 4 apresenta os resultados das três análises de regressão múltipla stepwise, identificando a variável dependente de cada modelo, seus regressores, os passos em que eles entraram, os coeficientes de correlação múltipla parcial $\left(R^{2} p\right)$, os coeficientes de correlação múltipla do modelo $\left(R^{2} m\right)$ e os betas padronizados de cada regressor.

Tabela 4: Três Modelos de Regressão Stepwise sobre as Variáveis Afetivas

\begin{tabular}{|c|c|c|c|c|c|}
\hline VARIÁVEIS DEPENDENTES & Regressores & Passos & $\begin{array}{c}\mathbf{R}^{2} \\
\text { Parciais } \\
\end{array}$ & $\begin{array}{c}\mathbf{R}^{2} \\
\text { Modelos } \\
\end{array}$ & $\begin{array}{c}\text { Betas } \\
\text { Padronizados }\end{array}$ \\
\hline 1.Comprometimento & PSO & 1 & $0,365 * *$ & & $0,510 * *$ \\
\hline \multirow[t]{2}{*}{ Organizacional Afetivo } & $\mathrm{COC}$ & 2 & $0,041 * *$ & $0,416 * *$ & $0,191 * *$ \\
\hline & PRO & 3 & $0,010 * *$ & & $0,114 * *$ \\
\hline \multirow[t]{3}{*}{ 2. Satisfação no Trabalho (EST) } & PSO & 1 & $0,318 * *$ & $0,342 * *$ & $0,489 * *$ \\
\hline & PRO & 2 & $0,018 * *$ & & $0,130 * *$ \\
\hline & $\mathrm{COC}$ & 3 & $0,006 *$ & & $0,083 *$ \\
\hline \multirow[t]{3}{*}{ 3. Envolvimento com o Trabalho } & PSO & 1 & $0,224 * *$ & $0,249 * *$ & $0,404 * *$ \\
\hline & $\mathrm{COC}$ & 2 & $0,018 * *$ & & $0,123 * *$ \\
\hline & PRO & 3 & $0,007 *$ & & $0,093 * *$ \\
\hline
\end{tabular}

Nota: $\mathrm{PSO}=$ percepção de suporte organizacional; $\mathrm{COC}=$ comprometimento organizacional calculativo; PRO = percepção de reciprocidade organizacional. ${ }^{* *} \mathrm{p}<0,01 ;{ }^{*} \mathrm{p}<0,05$.

O primeiro modelo, referente a comprometimento organizacional afetivo, conseguiu explicar, por meio dos três regressores, $41,6 \%$ da variância da variável dependente. Nota-se que percepção de suporte contribuiu com $36,5 \%$, percepção de reciprocidade com $4,1 \%$ e comprometimento calculativo com $1 \%$.

O segundo modelo, tendo como variável dependente satisfação no trabalho, produziu uma explicação de $34,2 \%$ por meio dos três regressores cognitivos. Percepção de suporte contribuiu com $31,8 \%$, percepção de reciprocidade com $1,8 \%$ e, finalmente, comprometimento calculativo com $0,6 \%$.

O terceiro modelo de regressão, efetuado sobre envolvimento com o trabalho, apontou uma porcentagem de $24,9 \%$ de explicação provida pelos regressores. 
Deste total, parte é originária da contribuição de 22,4\% de percepção de suporte, $1,8 \%$ de comprometimento calculativo e $0,7 \%$ de percepção de reciprocidade.

Percepção de suporte organizacional, constituída por crenças nutridas pelo empregado acerca do grau em que a organização se preocupa e promove o seu bemestar, revelou-se o antecedente cognitivo que trouxe maiores contribuições para explicar a variância das três variáveis afetivas. Estes resultados são consistentes com aqueles relatados na literatura internacional, visto que Shore e Tetrick (1991) obtiveram correlações significativas entre comprometimento afetivo e percepção de suporte, adotando a suposição, sem submetê-la a testes empíricos, de que o vínculo afetivo com a organização é desenvolvido a partir do momento em que o empregado percebe suporte, ou comprometimento, por parte da organização.

Quanto às variáveis comprometimento calculativo e percepção de reciprocidade, não foi encontrado na literatura nenhum estudo que as tivesse tomado como antecedentes de satisfação no trabalho ou envolvimento com o trabalho. Assim, os modelos de regressão analisados neste estudo e que as retiveram como regressores de satisfação no trabalho, envolvimento no trabalho e comprometimento afetivo, parecem ter produzido resultados inéditos nas investigações do comportamento organizacional.

Fica confirmada, pelo resultados obtidos neste estudo, a hipótese de que as variáveis cognitivas, incluídas no modelo de cidadania organizacional, seriam antecedentes das variáveis afetivas. Adicionalmente, evidências foram providas para a suposição de relações pós-cognitivas entre os antecedentes de comportamentos de cidadania.

\section{Conclusões e Recomendaçōes}

As evidências obtidas neste estudo confirmaram a adequação da seqüência de interdependência entre cognições, elos afetivos e gestos de cidadania organizacional prevista no modelo. As duas hipóteses do estudo foram confirmadas, visto que os elos afetivos com o trabalho (satisfação e envolvimento) e com a organização (comprometimento afetivo) foram mantidos como antecedentes diretos de comportamentos de cidadania, enquanto as três cognições (percepção de suporte organizacional, percepção de reciprocidade e comprometimento calculativo) se posicionaram como antecedentes dos elos afetivos. Neste sentido, conclui-se pela existência de uma relação pós-cognitiva entre os antecedentes cognitivos e afetivos de cidadania organizacional, o que significa existirem evidências nos resultados deste estudo, de que cognições sobre troca social enta- 
bulada com a organização antecedem os elos de natureza afetiva que o trabalhador estabelece com o seu trabalho e com a organização que o emprega.

Acreditando na existência de uma relação de troca social entre ele e a organização, especialmente quando percebe que ela se preocupa e promove o seu bem-estar (percepção de suporte), mostra-se retributiva às suas contribuições (percepção de reciprocidade) e ele ainda consegue avaliar perdas e custos associados ao rompimento das relações de trabalho que mantêm com a empresa (comprometimento calculativo), o trabalhador cria vínculos afetivos positivos com o trabalho (satisfação e envolvimento) e, ao mesmo tempo, desenvolve afetos positivos com a organização (comprometimento afetivo).

Tomando-se como ponto de análise do modelo as relações entre cognições e afetos e considerando-se a alta capacidade preditiva de percepção de suporte sobre as variáveis afetivas, superando em muito neste particular os seus outros dois correlatos cognitivos, entende-se que esta variável possa ser apontada como a principal base informacional do processo psicológico que antecede gestos de cidadania, demonstrando que estes atos têm uma sólida origem no grau em que a organização é percebida como comprometida com os seus empregados.

No outro segmento do modelo, mais especificamente no que concerne à predição direta de cinco classes de cidadania organizacional por meio de antecedentes afetivos, verificou-se que cada padrão comportamental de cidadania mensurado pela Escala de Comportamentos de Cidadania Organizacional (ECCO), poderia ser predito por variáveis afetivas específicas. As ações de criar um clima favorável à organização no ambiente externo, apresentar sugestões criativas ao sistema e cooperar com os colegas de trabalho, constituíram três padrões de cidadania para os quais o nível de comprometimento afetivo com a organização propiciou os valores mais elevados de explicação, superando a variável envolvimento com o trabalho naqueles dois modelos de regressão em que esta variável também foi retida como preditor. Estes resultados revelaram claramente a supremacia do elo afetivo com a organização sobre aqueles que ligam o indivíduo ao seu trabalho atual (satisfação e envolvimento), na predição dos três padrões de cidadania acima referidos.

Nota-se que os três padrões de cidadania citados acima constituem as classes de ações com maior conotação social, visto que a sua execução envolve interação com algum outro objeto, seja com as chefias do sistema durante a apresentação de sugestões criativas para o setor, com os colegas oferecendo colaboração, seja com indivíduos, externos ao meio organizacional, para divulgar informações que concretizem uma imagem positiva da organização.

Os outros dois padrões de cidadania, proteção ao sistema e autotreinamento 
para execução do trabalho, são desencadeados por uma base cognitivista comum aos outros três padrões já analisados, mas diretamente associados a elos afetivos com o trabalho (satisfação e envolvimento) e não à organização (comprometimento afetivo). Estas duas classes de ações, embora beneficiem o sistema, porque permitem maior longevidade para seus recursos e disponibilidade de potencial humano mais qualificado para o desempenho das tarefas, não constituem atos essencialmente de interação social, porque ambas estão mais restritas a gestos individuais dos empregados, voltados inicialmente para o patrimônio da organização ou para o aprimoramento individual do trabalhador. Esta pode ser uma possível explicação para o fato de terem como antecedentes diretos as variáveis satisfação e envolvimento com o trabalho. Assim, devido à supremacia de percepção de suporte como antecedente de satisfação e envolvimento, considera-se que novamente as crenças acerca do comprometimento da organização com seus empregados, leva-os a se envolverem e a se sentirem satisfeitos com o trabalho que realizam, permitindo que atos até anônimos de proteção ao sistema ou de autotreinamento sejam espontaneamente emitidos.

As evidências oferecidas pelo presente estudo, no que se refere à participação de percepção de suporte e comprometimento organizacional afetivo, permitem entender que o processo psicológico de troca social entre empregado e organização estaria largamente assentado no compromisso mútuo que se estabelece entre as duas partes envolvidas nesta permuta: o trabalhador e a organização. Estas noções sinalizam que primeiro a organização deve ser percebida como comprometida com os seus empregados para que, em seguida, eles (os empregados) se comprometam afetivamente com a organização e a ela ofereçam determinados gestos de cidadania organizacional.

Torna-se relevante acrescentar às conclusões deste estudo um sinal de cuidado quanto aos resultados obtidos sobre três dos cinco fatores de comportamentos de cidadania organizacional avaliados pela ECCO. Os fatores que aferem gestos de proteção ao sistema, de autotreinamento e de cooperação com os colegas de trabalho são subescalas da $\mathrm{ECCO}$, com índices de precisão frágeis $(\alpha<0,70)$, tornando os resultados que envolvem estes fatores merecedores de análises futuras.

Quando o modelo pós-cognitivo, proposto neste estudo, for ser utilizado para analisar a multideterminação de ações dos trabalhadores envolvidas em uma troca de natureza econômica entre empregado e organização, tais como produtividade, desempenho, rotatividade e absenteísmo, acredita-se que a base informacional do processo de permuta deva ser constituída por cognições distintas daquelas aqui utilizadas como antecedentes de cidadania organizacional. Como a troca econômica é, teoricamente, sustentada por contratos formalizados entre empregado e or- 
ganização, a sua base informacional deveria ser constituída por elementos cognitivos que representassem crenças ou percepções do trabalhador sobre a honestidade organizacional no cumprimento de obrigações contratuais. Nestes casos, aventa-se a possibilidade de que conceitos referentes à percepções de justiça distributiva e de justiça de procedimentos, bem como à percepção de confiança inspirada pela organização nos seus empregados, possam ser incluídos no modelo para compor a base informacional do processo de troca econômica.

\section{ReferênCiAs Bibliográficas}

AJZEN, I.;

FISHBEIN, M.

Understanding attitudes and predicting social behavior. New Jersey: Prentice-Hall, 1980.

BATEMAN, T. S.;

ORGAN, D. W.

Job satisfaction and the good soldier: the relationship between affect and employee "citizenship". Academy of Management Journal, v. 26, p. 587-595, 1983.

BECKER, H. S.

Notes on the concept of commitment. American Journal of Psychology, v. 66, p. 32-40, 1960.

EISENBERGER, R. et al.

Perceived organizational support. Journal of Applied Psychology, v. 71, p. 500-507, 1986.

GOULDNER, A. W.

The norm of reciprocity: a preliminary statement. American Sociological Review, v. 25, p. 161-178, 1960.
KATZ, D.;

KAHN, R. L.

Psicologia social das organizações. São Paulo: Atlas, 1978.

LAZARUS, R. S.

Thoughts on the relation between emotion and cognitions. American Psychologist, v. 37, p. 1019-1024, 1982.

MOORMAN, R. H.

Relationship between organizational justice and organizational citizenship behaviors: do fairness perceptions influence employee citizenship? Journal of Applied Psychology, v. 76, p. 845-855, 1991.

MOTOWIDLO, S. J.

Does job satisfaction lead to consideration and personal sensitivity? Academy of Management Journal, v. 27, p. 910-915, 1984. 
ORGAN, D. W.

The motivational basis of organizational citizenship behavior. In: STAW, B. M.; CUMMINGS, L. L. (Eds.). Research in organizational behavior. New York: Jai Press, 1990. v. 12. p. 4372.

ORGAN, D. W.;

KONOVSKY, M.

Cognitive versus affective determinants of organizational citizenship behavior. Journal of Applied Psychology, v. 74, p. 157-164, 1989.

\section{PUFFER, S. M.}

Prosocial behavior, noncompliant behavior, and work performance among commission sales people. Journal of Applied Psychology, v. 72, p. 615-621, 1987.

SHORE, L. M.;

TETRICK, L. E.

A construct study of the survey of perceived organizational support. Journal of Applied Psychology, v. 76, p. 637-643, 1991.
SIQUEIRA, M. M. M.

Antecedentes de comportamentos de cidadania organizacional: a análise de um modelo pós-cognitivo. Brasília, 1995. Tese (Doutorado em Psicologia) - Instituto de Psicologia, Universidade de Brasília.

SMITH, C. A.; ORGAN, D. W.;

NEAR, J. P.

Organizational citizenship behavior: it's nature, and antecedents. Journal of Applied Psychology, v. 68, p. 653-663, 1983.

WATSON, D.; CLARK, L. A.

Negative affectivity: the disposition to experience aversive emotional states. Psychological Bulletin, v. 96, p. 465-490, 1984.

WATSON, D.; TELLEGEN, A.

Toward a consensual structure of mood. Psychological Bulletin, v. 98, p. 219-235,1985. 